\title{
Targeting of the breast cancer microenvironment with a potent and linkable oxindole based antiangiogenic small molecule
}

\author{
Orestis Argyros ${ }^{1}$, Theodoros Karampelas ${ }^{1}$, Aimilia Varela ${ }^{2}$, Xenophon Asvos $^{3}$, \\ Athanasios Papakyriakou, ${ }^{4}$ Adamantia Agalou5, Dimitris Beis ${ }^{5}$, Constantinos H. \\ Davos $^{2}$, Demosthenes Fokas ${ }^{3}$, Constantin Tamvakopoulos ${ }^{1}$ \\ ${ }^{1}$ Division of Pharmacology-Pharmacotechnology, Biomedical Research Foundation Academy of Athens, Athens, 11527, Greece \\ ${ }^{2}$ Cardiovascular Research Laboratory, Clinical, Experimental Surgery and Translational Research Center, Biomedical Research \\ Foundation Academy of Athens, Athens, 11527, Greece \\ ${ }^{3}$ Laboratory of Medicinal Chemistry, Department of Materials Science and Engineering, University of Ioannina, Ioannina, \\ 45110, Greece \\ ${ }^{4}$ Laboratory of Chemical Biology of Natural Products and Designed Molecules, Institute of Physical Chemistry, N.C.S.R \\ "Demokritos", Athens, 15310, Greece \\ ${ }^{5}$ Developmental Biology, Biomedical Research Foundation Academy of Athens, Athens, 11527, Greece \\ Correspondence to: Constantin Tamvakopoulos, email: ctamvakop@bioacademy.gr \\ Demosthenes Fokas, email: dfokas@cc.uoi.gr
}

Keywords: angiogenesis, sunitinib analogue, tumor targeting, breast cancer, tumor microenvironment

Received: June 29, 2016

Accepted: March 22, 2017

Published: March 31, 2017

Copyright: Argyros et al. This is an open-access article distributed under the terms of the Creative Commons Attribution License (CC-BY), which permits unrestricted use, distribution, and reproduction in any medium, provided the original author and source are credited.

\section{ABSTRACT}

The clinical efficacy of antiangiogenic small molecules (e.g., sunitinib) in breast carcinoma has largely failed with substantial off-target toxicity. We rationally designed and evaluated preclinically a novel sunitinib analogue, SAP, with favourable pharmacological properties and the ability to be readily conjugated to a targeting peptide or antibody for active tumour targeting.

SAP was evaluated in silico and in vitro in order to verify target engagement (e.g., VEGFR2). Pharmacokinetic and biodistribution parameters were determined in mice using LC-MS/MS. SAP efficacy was tested in two breast cancer xenograft and two syngeneic animal models and pharmacodynamic evaluation was accomplished using phosphokinase assays and immunohistochemistry. Cardiac and blood toxicity of SAP were also monitored.

SAP retained the antiangiogenic and cytotoxic properties of the parental molecule with an increased blood exposure and tumor accumulation compared to sunitinib. SAP proved efficacious in all animal models. Tumors from SAP treated animals had significantly decreased Ki-67 and CD31 markers and reduced levels of phosphorylated AKT, ERK and S6 compared to vehicle treated animals. In mice dosed with SAP there was negligible hematotoxicity, while cardiac function measurements showed a reduction in the percentage left ventricular fractional shortening compared to vehicle treated animals.

In conclusion, SAP is a novel rationally designed conjugatable small antiangiogenic molecule, efficacious in preclinical models of breast cancer.

\section{INTRODUCTION}

Breast cancer $(\mathrm{BrCa})$ is the most common malignancy among women and is clinically stratified into three major types depending on the expression of the estrogen (ER) and progesterone receptor (PR), or amplification/overexpression of the receptor tyrosine kinase (RTK) HER2/neu $[1,2]$. In contrast, the triple-negative breast cancer (TNBC) type lacks expression of any of these three receptors and is generally characterized by poor prognosis [3]. 
A hallmark of $\mathrm{BrCa}$ is angiogenesis, a tightly orchestrated process between stromal and tumor epithelial cells [6]. Key stimuli are provided by proangiogenic factors such as the vascular endothelial (VEGF) and the platelet derived growth factor (PDGF) together with their respective receptors. Preclinical studies have shown that inhibition of the VEGF pathway impedes tumor growth and clinically the VEGF-neutralizing antibody bevacizumab was the first antiangiogenic treatment in $\mathrm{BrCa}$ due to the E2100 trial [7]. Subsequent failure to reproduce the results of the E2100 trial lead to withdrawal of the indication of bevacizumab in $\mathrm{BrCa}$ treatment [8].

Antiangiogenic small molecules (e.g., sunitinib) have initially produced a robust preclinical efficacy in $\mathrm{BrCa}$ [9-12] justifying the initiation of several clinical trials, where sunitinib was evaluated in combination therapies with cytotoxic molecules. Unfortunately, the majority of such combinational efforts failed to meet the designed primary end points and trials were discontinued, either due to the lack of efficacy, or dose limitations due to toxicity [13]. For example, the SUN1064 study of sunitinib in combination with docetaxel in $\mathrm{BrCa}$ patients did not show a statistically significant improvement in PFS compared with docetaxel alone [14]. A similar result was obtained in the SUN1099 study of sunitinib combined with capecitabine [15]. However, a sophisticated treatment scheme employing sunitinib coadministration with trastuzumab (an antibody targeting the HER2) generated encouraging results in a phase II study of HER2 positive patients [16]. In addition, the recent initiation of a clinical trial (NCT02074878) in TNBC patients where sunitinib was administered with crizotinib (a MET inhibitor) highlighted that sunitinib still holds promise in $\mathrm{BrCa}$ clinical practice and further efforts are necessary especially in hard to treat TNBC and HER2 positive patients. The details behind the clinical shortcomings of sunitinib in $\mathrm{BrCa}$ are not entirely clear but suggested explanations include the growing evidence that $\mathrm{BrCa}$ angiogenesis is driven by more than just VEGF, so inhibition of many other proangiogenic kinases might be necessary; the activation of cancer stem cells that overcome tumor remission [10]; and certainly the limitation of administering a higher drug dose due to offtarget toxicities such as left ventricular (LV) dysfunction and overt heart failure frequently encountered due to depletion of coronary microvascular pericytes [17].

We have recently demonstrated that conjugation of a rationally designed analogue of sunitinib (called SAN1) to a decapeptide moiety (generating SAN1GSC) alleviated such toxicity possibly due to the ability of SAN1GSC to selectively deliver the pharmacophore to the tumor microenvironment, as shown in a castration resistant prostate cancer animal model [18]. SAN1 was also active in $\mathrm{BrCa}$ cell lines but its development encountered various hurdles, namely a low synthetic yield (71\%), and the limited conjugation options that the free hydroxyl group of SAN1 allowed for. Thus we have now opted to generate a new sunitinib analogue, to pharmacologically equivalent to sunitinib or SAN1 that will also allow for additional conjugation possibilites. The pivotal therapeutic role of conjugated small molecules in $\mathrm{BrCa}$ has been strengthened by the recent success of T-DM1, allowing us to design a distinct therapeutic approach based on implementing an antiangiogenic agent conjugated to a targeting peptide or antibody in order to treat $\mathrm{BrCa}$ at the tumor microenvironment rather than solely at the individual cancer cell.

Herein we present the synthesis and preclinical evaluation of a novel piperazine based analogue of sunitinib (called SAP). SAP was rationally designed to maintain the potency of sunitinib but with the advantage of targeted delivery by allowing for swift amine-based conjugation chemistries with peptides or antibodies. In addition, the piperazine functional group of SAP is also predicted to augment the compound's anticancer effects [24-26], while pharmacologically SAP is characterised by lower $\operatorname{LLogP}$, higher polar surface area and improved aqueous solubility.

\section{RESULTS}

\section{Synthesis of SAP}

The synthetic route for SAP is shown in Figure 1A while the accurate chemical structure was verified by ${ }^{1} \mathrm{H}$ Nuclear Magnetic Resonance (NMR) (Figure 1B). SAP retained the indolin-2-one core of sunitinib responsible for RTK inhibition, while it provided a handle for conjugation to a targeting peptide or antibody through the amino group of piperazine. Figure $1 \mathrm{C}$ depicts the MS features as well as some key properties of SAP. The lipophilicity of SAP was calculated to be lower than sunitinib ( $\log P=1.5$ vs 2.9 of sunitinib), and the calculated 2D PSA of SAP is higher in comparison to sunitinib (85.5 $\AA^{2}$ vs $73.5 \AA^{2}$ of sunitinib). The calculated percent absorption ( $\% \mathrm{ABS}=80$, calculated using: $\% \mathrm{ABS}=109-0.345 \mathrm{PSA}$ ), and the degree of blood brain barrier permeability $(\log B \mathrm{~B}=-0.9$ calculated using: $\log \mathrm{BB}=-0.0148$ PSA $+0.152 \mathrm{cLog} \mathrm{P}+0.139)$ suggest a good absorption and poor brain permeability profile of SAP with respect to other angiogenesis inhibitors [27]. A representative mass spectrum for SAP and an LC-MS/MS chromatogram (depicting the $\mathrm{Z}$ and $\mathrm{E}$ isomers of SAP) are shown in Figure 1D-1F.

\section{Molecular docking}

Molecular docking calculations were performed for SAP in comparison with sunitinib, which were based on the X-ray structures of VEGFR-2 and KIT complexes with sunitinib, and a homology model of PDGFR- $\beta$ (Supporting Information SI2). The inhibition constants of SAP and sunitinib were estimated to be comparable (at the low 
nanomolar range), and representative molecular models of SAP bound to the ATP-binding site of SAP complexed with these RTKs are shown in Figure 2A.

\section{Biochemical kinase assay}

The potency of SAP was evaluated in biochemical assays employing the known RTK targets of sunitinib (VEGFR-2, PDGFR- $\beta$, KIT, FLT3 and RET) and against the EGFR as a negative control (Figure 2B). SAP inhibited most of these RTKs with comparable affinity with respect to sunitinib $\left(\mathrm{IC}_{50}=61-102 \mathrm{nmol} / \mathrm{L}\right)$, a result confirming out design strategy. An interesting observation was the superior potency of SAP over sunitinib in inhibiting RET $\left(\mathrm{IC}_{50}=102\right.$ vs $\left.699 \mathrm{nmol} / \mathrm{L}\right)$, a finding that merits further investigation.

\section{Cellular ligand-dependent phosphorylation assay}

The inhibition of phosphorylation of VEGFR-2 and PDGFR- $\beta$ was further confirmed in HUVEC and NIH/3T3 cells, using a Western blot based cellular ligand-dependent phosphorylation assay (Figure 2C). The calculated cellular $\mathrm{IC}_{50}$ values for sunitinib were $24 \pm 12 \mathrm{nmol} / \mathrm{L}$ (for VEGFR-2) and $72 \pm 19 \mathrm{nmol} / \mathrm{L}$ (for PDGFR- $\beta$ ) respectively. Similar potencies were observed for SAP with cellular $\mathrm{IC}_{50}$ values of $52 \pm 14 \mathrm{nmol} / \mathrm{L}$ for VEGFR-2 and $76 \pm 22 \mathrm{nmol} / \mathrm{L}$ for PDGFR- $\beta$.

\section{Cytotoxicity and antimetastatic cellular studies}

The antiproliferative effect of SAP was assessed in several cell lines including three luminal (MCF7, T47D, ZR75-1), one basal TNBC (MDA-MB-231) and two HER2 amplified (HCC1954, SKBR3) BrCa subtypes, as well as the endothelial cell line HUVEC. Results and comparative $\mathrm{IC}_{50}$ values are presented in Figure 2D. SAP was equipotent to sunitinib, but also to our previously generated SAN1 molecule [18] in all cell lines with $\mathrm{IC}_{50}$ values ranging from $6.5 \pm 2.4 \mu \mathrm{mol} / \mathrm{L}$ to $15.8 \pm 1.7 \mu \mathrm{mol} / \mathrm{L}$.

The antimetastatic potential of SAP was demonstrated in the MDA-MB-231 cell line using a
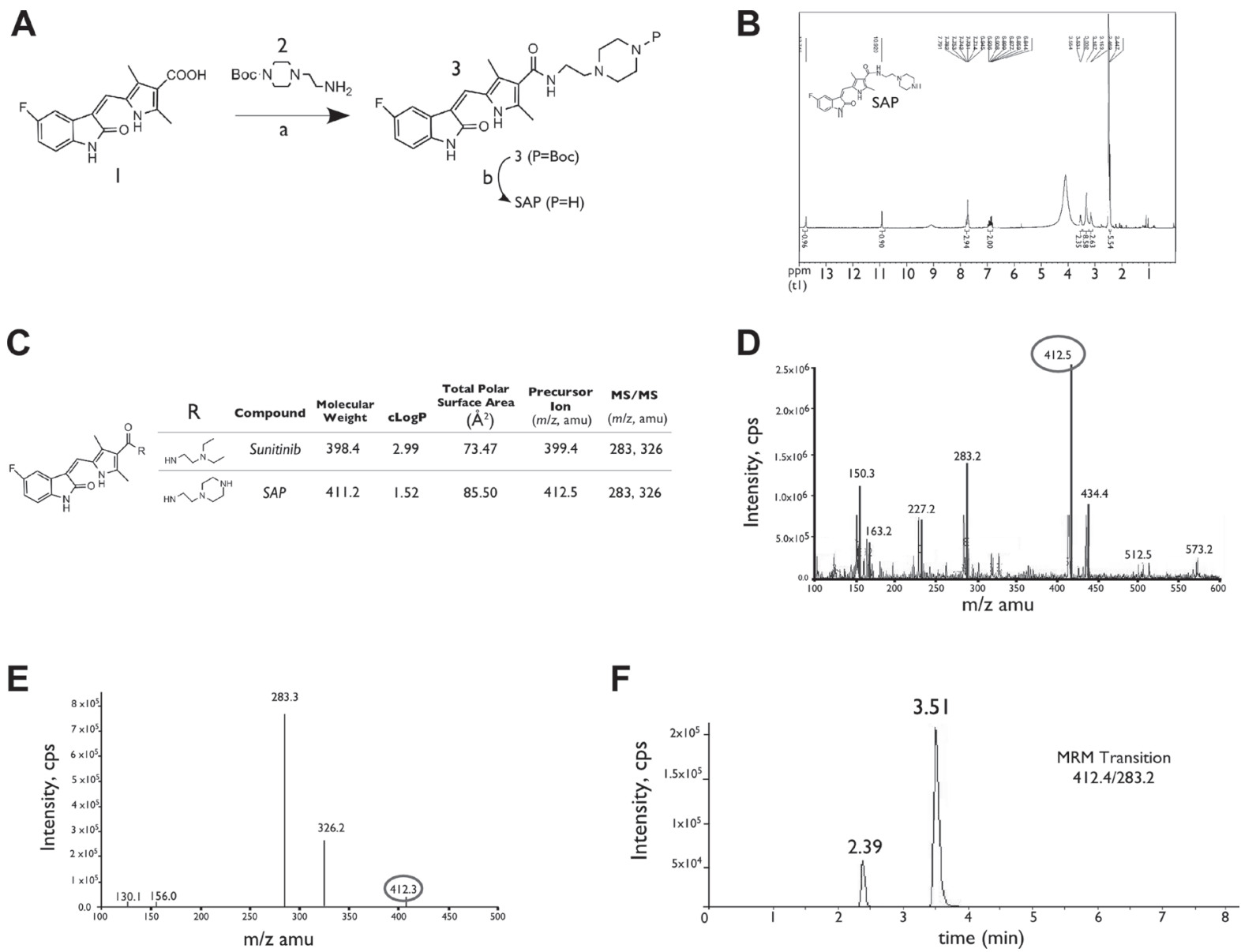

Figure 1: Synthesis and characterization of SAP. (A) Synthesis of SAP from the available acid intermediate 1. Reagents and conditions: (a) DMF, EDCI, HOBt, $\mathrm{NE}_{\mathrm{t} 3}$, rt: room temperature; (b) $\mathrm{CH}_{2} \mathrm{C}_{12}$, TFA, rt. (B) NMR spectrum of SAP. (C) Key physical properties for SAP and sunitinib. (D) Representative positive electrospray ionization mass spectra of SAP showing the main ionized form (M+1, $m / z$ 412.5). (E) MS/MS analysis of the parent ion with $\mathrm{m} / z 412.5$ and the formation of product ions with $\mathrm{m} / z 283.3$ and $\mathrm{m} / \mathrm{z} 326.2$ (F) LC/MRM chromatogram of SAP, demonstrating the presence of $\mathrm{E}$ and $\mathrm{Z}$ geometric isomers. 
wound healing assay and various drug concentrations. Results showed that SAP had similar potency to sunitinib at inhibiting cell migration based on cellular gap closure at $10 \mu \mathrm{mol} / \mathrm{L}$ (Supplementary Figure 1).

\section{Pharmacokinetic evaluation of SAP}

The in vitro efficacy of SAP was followed by its pharmacokinetic evaluation in mice. Initially, the PK parameters of SAP were compared in an oral versus IP administration (Figure 3). When dosed orally, SAP achieved maximum blood concentrations at $1 \mathrm{~h}$ of $0.2 \pm 0.1 \mu \mathrm{mol} / \mathrm{L}$ with an $\mathrm{AUC}_{0-24 \mathrm{~h}}$ of $2.5 \pm 2.3 \mathrm{~h} \times \mu \mathrm{mol} / \mathrm{L}$. Higher blood exposure was observed following an IP administration, where SAP reached its highest blood concentrations at $0.25 \mathrm{~h}$ with a Cmax of $27 \pm 3.6 \mu \mathrm{mol} / \mathrm{L}$ and an $\mathrm{AUC}_{0-24 \mathrm{~h}}$ of $50.3 \pm 15.3 \mathrm{~h} \times \mu \mathrm{mol} / \mathrm{L}$. No signs of discomfort or overt toxicity were observed in any of the treated mice. Interestingly these pharmacokinetic measurements were superior to sunitinib when directly compared with previous results using the same administration route (IP) and an equimolar dose (Cmax for sunitinib was $6.5 \pm 0.9 \mu \mathrm{mol} / \mathrm{L}$ at $0.25 \mathrm{~h}$ with an

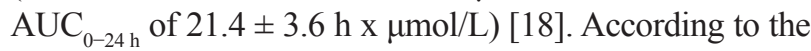
biochemical assays SAP concentrations of approximately $0.1 \mu \mathrm{mol} / \mathrm{L}$ were needed for the inhibition of the target kinases (Figure 2A-2C). The pharmacokinetic experiments suggested that following IP dosing (at $100 \mathrm{umol} / \mathrm{Kg}$ ), concentrations of at least $0.1 \mu \mathrm{mol} / \mathrm{L}$ could be sustained for more than $8 \mathrm{~h}$ post-dose $\left(\mathrm{SAP} \mathrm{C}_{8 \mathrm{~h}}=0.93 \pm 0.3 \mu \mathrm{mol} / \mathrm{L}\right)$, indicating that an IP dose at $100 \mathrm{umol} / \mathrm{Kg}$ should be the preferred route of administration for the subsequent preclinical efficacy studies in mice.

\section{In vivo antitumor efficacy in xenografted mice}

In order to determine whether SAP treatment could eradicate tumors as effectively as sunitinib in two aggressive (ER and PR independent) forms of $\mathrm{BrCa}$, we generated xenografted mice bearing established tumors using the HCC1954 or MDA-MB-231 cell lines. Pharmacological treatment was initiated when tumors reached $100-150 \mathrm{~mm}^{3}$ for a total period of 18 days, using a dose of each molecule at $100 \mu \mathrm{mol} / \mathrm{Kg} /$ day. At the end of the treatment period (d18) for the HCC1954 animal model (Figure 4A) the average tumor size was $428 \pm 101 \mathrm{~mm}^{3}$ for vehicle treated mice, significantly $(P<.001)$ higher compared to SAP $\left(76 \pm 52 \mathrm{~mm}^{3}\right)$ or sunitinib $\left(152 \pm 57 \mathrm{~mm}^{3}\right)$ treated mice.

Similarly for MDA-MB-231 tumor bearing animals, both sunitinib and SAP were able to significantly $(P<.001)$ delay tumor growth compared to vehicle treated animals. SAP treated animals had an average tumor size at $\mathrm{d} 18$ of $265 \pm 98 \mathrm{~mm}^{3}$, sunitinib treated animals averaged $367 \pm 117 \mathrm{~mm}^{3}$ while vehicle treated mice reached an average size of $1361 \pm 250 \mathrm{~mm}^{3}$ (Figure 4B). Interestingly, a comparison between SAP and sunitinib at

\section{A}

\begin{tabular}{r|ccc}
$\begin{array}{c}\text { Estimated Ki } \\
\text { (nmol/L) }\end{array}$ & VEGFR-2 & PDGFR-b & KIT \\
\hline Sunitinib & 109 & 43 & 85 \\
SAP & 24 & 4 & 14
\end{tabular}
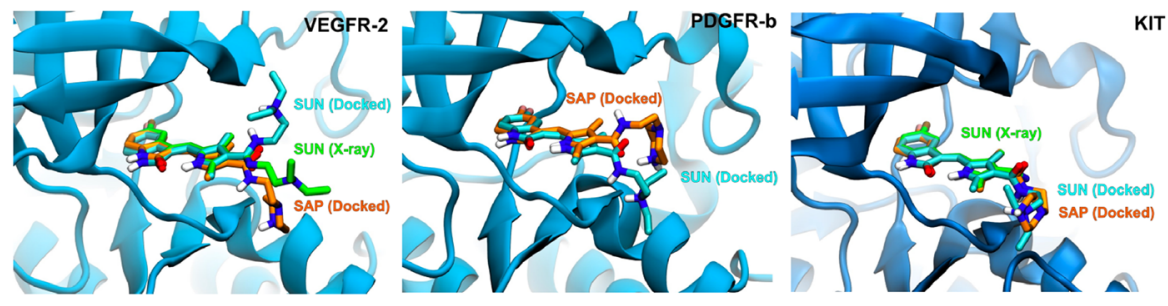

B

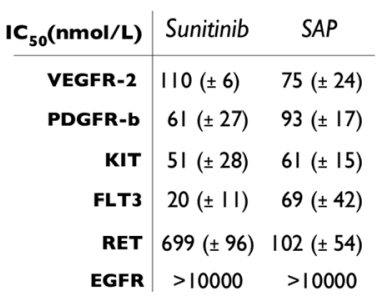

C

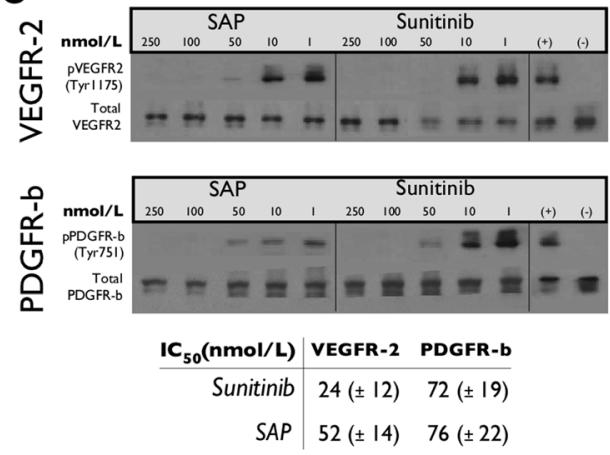

D

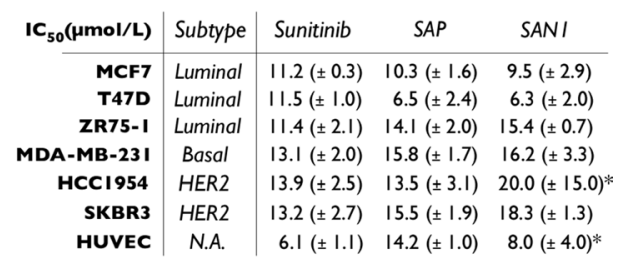

Figure 2: In silico and in vitro analysis of SAP. (A) Docking results for SAP and sunitinib. Molecular models of the ATP-binding site of VEGFR-2, PDGFR- $\beta$ and KIT illustrating the predicted bound poses of sunitinib (SUN, cyan sticks) and SAP (orange sticks) in comparison with the crystallographic conformation of sunitinib (SUN, green sticks) of VEGFR2 and KIT. (B) Summary of in vitro kinase activity in multiple RTKs in the presence of sunitinib or SAP $( \pm$ SD). (C) Cell based autophosphorylation assay for VEGFR-2 and PDGFR- $\beta$ in the presence of sunitinib or SAP $( \pm$ SD). (D) MTT cytotoxicity assay in a panel of BrCa cell lines and HUVEC. *historical data. N.A: Not Active. 
d18 revealed that SAP was statistically more efficacious $(P<.001)$ Neo-angiogenesis was evident upon sacrifice in both $\mathrm{BrCa}$ xenograft models, for vehicle treated mice (Figure 4C-4D), while only traces of newly formed blood vessels were noted for SAP and sunitinib treated animals consistent with their antiangiogenic mechanism of action.

The average tumor weights upon sacrifice for the HCC1954 BrCa animal model were $0.26 \pm 0.07 \mathrm{~g}$ for vehicle treated mice (Figure 4E), significantly $(P<.001)$ heavier over SAP $(0.05 \pm 0.02 \mathrm{~g})$ and sunitinib $(0.07 \pm 0.03 \mathrm{~g})$. In the MDA-MB-231 animal model the respective tumor weights were $0.8 \pm 0.2 \mathrm{~g}$ for vehicle, $0.2 \pm 0.1 \mathrm{~g}$ for SAP and $0.4 \pm 0.1 \mathrm{~g}$ for sunitinib, with both drugs at compared to vehicle treated animals $(P<.001)$. In both animal models, no changes in animal total body weight (data not shown), or overt toxicity was observed.

Concentrations of sunitinib and SAP in blood and tumor tissue were measured at $1 \mathrm{~h}$ after a final dose on $\mathrm{d} 18$ for both the HCC1954 and MDA-MB-231 animal models (Figure 4F). For the HCC1954 xenograft, the blood $\mathrm{C}_{1 \mathrm{~h}}$ was $10.3( \pm 3.7) \mu \mathrm{mol} / \mathrm{L}$ for sunitinib and $12.8( \pm 1.6)$ $\mu \mathrm{mol} / \mathrm{L}$ for SAP, while the respective $\mathrm{C}_{1 \mathrm{~h}}$ in the tumor tissue was $7.7( \pm 2.0) \mu \mathrm{mol} / \mathrm{L}$ for sunitinib and 8.5 $( \pm 1.2) \mu \mathrm{M}$ for SAP, generating a tumor/blood $(\mathrm{t} / \mathrm{b})$ ratio of 0.8 for sunitinib and 0.7 for SAP (Figure 4G). In the MDAMB-231 animal model the $\mathrm{C}_{1 \mathrm{~h}}$ in the blood for sunitinib and SAP was $10.8( \pm 2.1) \mu \mathrm{mol} / \mathrm{L}$ and $14.8( \pm 2.4) \mu \mathrm{mol} / \mathrm{L}$ respectively, while the values for intratumoral drug levels were $41.6( \pm 5) \mu \mathrm{mol} / \mathrm{L}$ and $64.4( \pm 14.3) \mu \mathrm{mol} / \mathrm{L}$. The $\mathrm{t} / \mathrm{b}$ ratio for the MDA-MB-231 xenograft was 4.0 for sunitinib and 4.5 for SAP (Figure 4G). Despite the fact
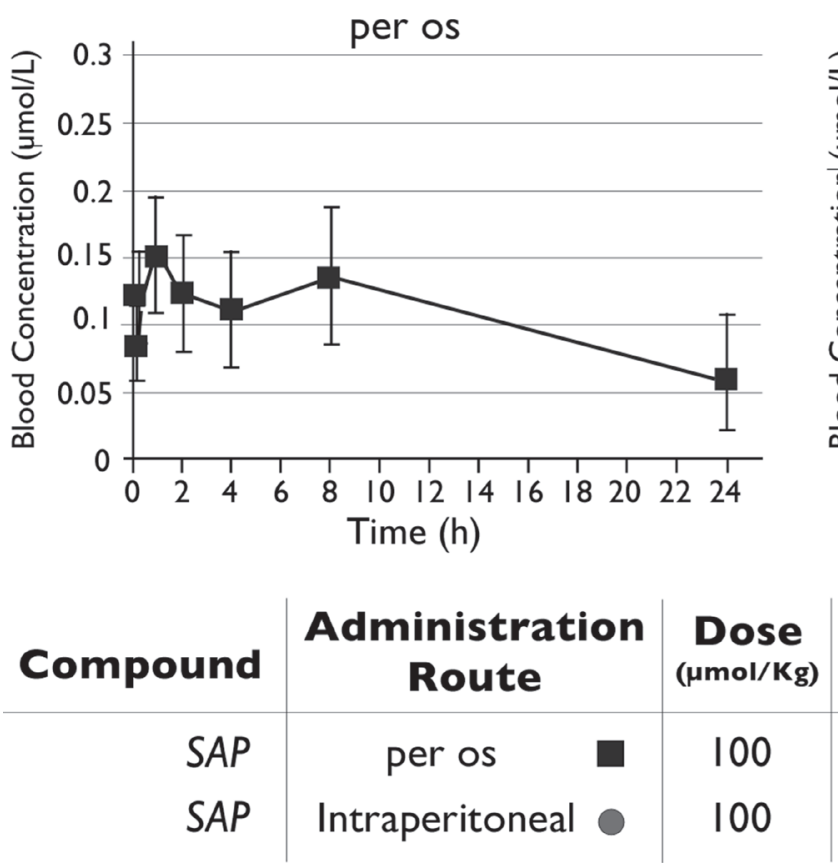

that sunitinib is more lipophilic in comparison to SAP (see clog $P$ values), the high intratumoral concentrations of SAP in both xenografts may be due to a lower tissue clearance in comparison to sunitinib, a property that is favorable for tumor targeting.

\section{In vivo target modulation investigation.}

Insights into the molecular mechanism responsible for the in vivo efficacy of SAP and sunitinib were obtained by histological, immunohistochemical and target modulation analysis of tumors harvested from all animals on the day of sacrifice (d18) for both the HCC1954 and MDA-MB-231 animal models (Figure 5).

For HCC1954 treated mice, the IHC analysis in tumor sections using antibodies against Ki-67 and CD31 showed a marked reduction in cell proliferation and reduced angiogenesis in SAP and sunitinib compared to vehicle treated specimens (Figure 5A). The Ki-67 assessed PI of mice treated with SAP was $19.2 \pm 4.9 \%$, and $22.9 \pm 7.8 \%$ for sunitinib (both at $P<.001$ over vehicle treated mice) whereas for vehicle treated mice it was $82.3 \pm 11.1 \%$. The average number of CD31+ cells in tumor sections of mice treated with SAP were 16.6 \pm 7.1 $(P<.001$ versus vehicle treated mice $)$, and $21.6 \pm 9.0$ $(P<.001$ compared to vehicle treated mice) for sunitinib versus $42.4 \pm 8.3$ for vehicle treated mice (Figure 5A).

In order to gain a deeper understanding of the mechanism of action of SAP in treated mice, we investigated the phosphorylation status of 18 kinases in extracts of tumor tissue and compared it to tumor extracts

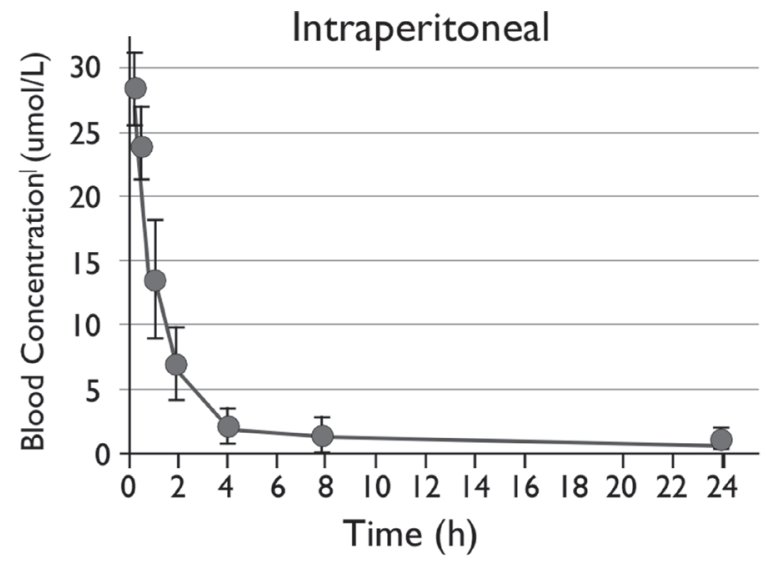

\begin{tabular}{|c|c|c|}
\hline $\begin{array}{c}C_{\max } \\
(\mu \mathrm{mol} / \mathrm{L}) \\
( \pm \text { S.D. })\end{array}$ & $\underset{\text { (h) }}{\operatorname{tmax}}$ & $\begin{array}{l}\text { AUC } 0-24 \text { ( } \pm \text { S.D. }) \\
\text { (h) } \times(\mu \mathrm{mol} / \mathrm{L})\end{array}$ \\
\hline $0.2( \pm 0.1)$ & I & $2.5( \pm 2.3)$ \\
\hline $27( \pm 3.6)$ & 0.25 & $50.3( \pm 15.3)$ \\
\hline
\end{tabular}

Figure 3: Pharmacokinetic evaluation of SAP. Female NOD/SCID mice $(n=6)$ were dosed per os or IP with SAP $(100 \mu \mathrm{mol} / \mathrm{Kg})$ and blood samples were collected at selected time points. Drug levels of SAP were monitored by LC-MS/MS. The AUC for each treatment was calculated as a measure of drug exposure over time. 
of vehicle and sunitinib treated mice (Figure 5B). A marked downregulation of pErk1/2 (Thr202/Tyr204), pAkt (Ser473) and pGSK3 (Ser9) was noted in SAP and sunitinib treated versus vehicle treated mice, consistent with the multikinase phosphorylation inhibition ability of sunitinib and the designed SAP analogue. High levels of $\mathrm{pBad}$ (Ser112) protein indicative of increased levels of apoptosis were seen in all treatment groups. The reduced levels of pErk1/2 (Thr202/Tyr204) were verified in subsequent IHC experiments (Figure 5C). A similar analysis was performed in tumor sections from the MDA-MB-231 xenografted mice (Figure 5D). In this case, the Ki-67 assessed PI of mice treated with SAP was $20.11 \pm 4.5 \%$, for sunitinib the respected value was $20.9 \pm 5.6 \%(P<.001$ for both drugs compared to vehicle treated mice), whereas for vehicle it was $97.4 \pm 7.2 \%$. The average number of CD31+ cells in tumor sections of mice treated with SAP were $25.7 \pm 11.8$, for sunitinib $28.1 \pm 11.3$ (both at $P<.001$ over vehicle treated mice) and for vehicle $50.6 \pm 10.2$.

Analysis of the phosphorylation status of 18 kinases in extracts of tumor tissue (Figure 5E), revealed a marked decrease mainly of pErk1/2 (Thr202/Tyr204), pAkt (Ser473) and pS6 (Ser235/236) in SAP and sunitinib treated versus vehicle treated mice. Again, high levels of pBad (Ser112) protein indicative of increased levels of apoptosis were seen in all treatment groups. The reduced levels of pErk1/2 (Thr202/Tyr204) and pS6 (Ser235/236) were verified in subsequent IHC experiments (Figure 5F).

As an additional in vivo model of SAP efficacy we employed the well established zebrafish angiogenesis inhibition assay. We used $T g(k d r l: g f p)^{\text {s843 }}$ transgenic embryos treated from 24 to $48 \mathrm{hpf}$ with equimolar amounts of either SAP or sunitinib. In $T g(k d r l: g f p)^{\text {s843 }}$
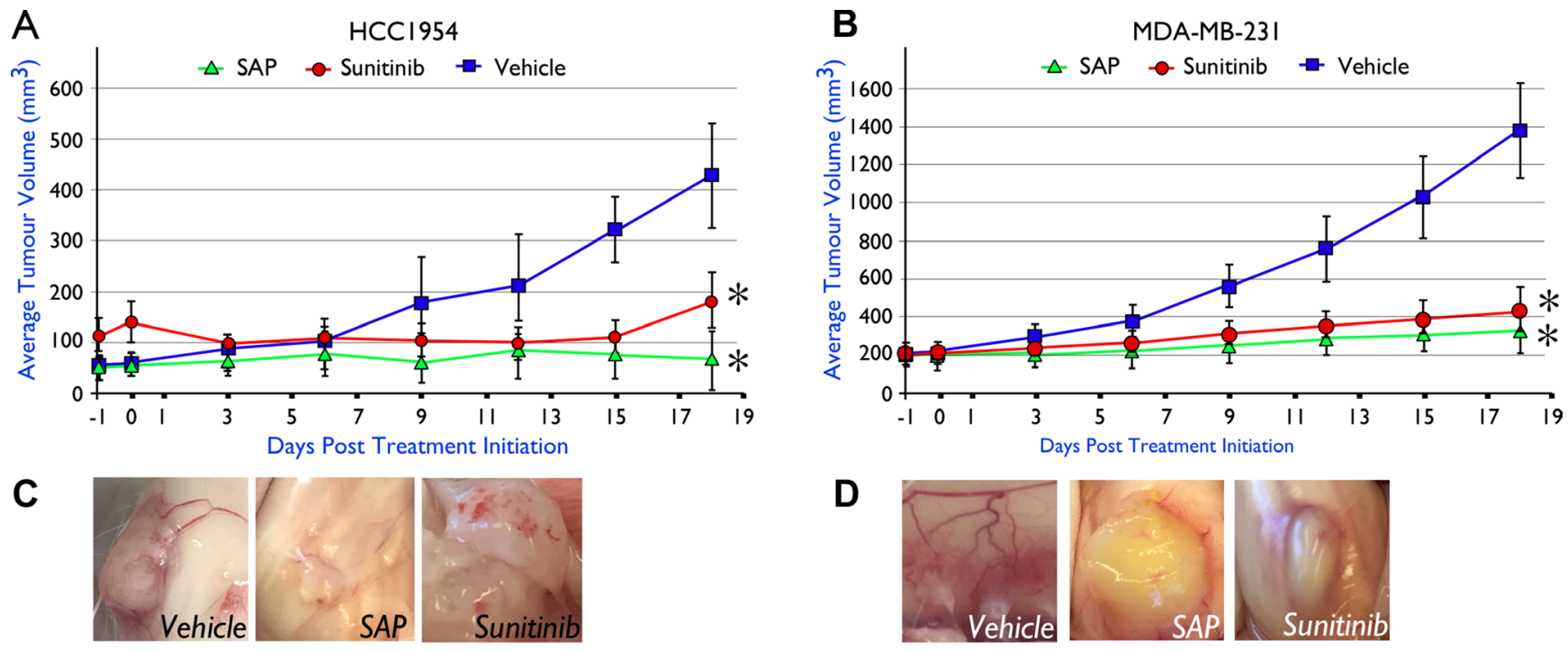

D
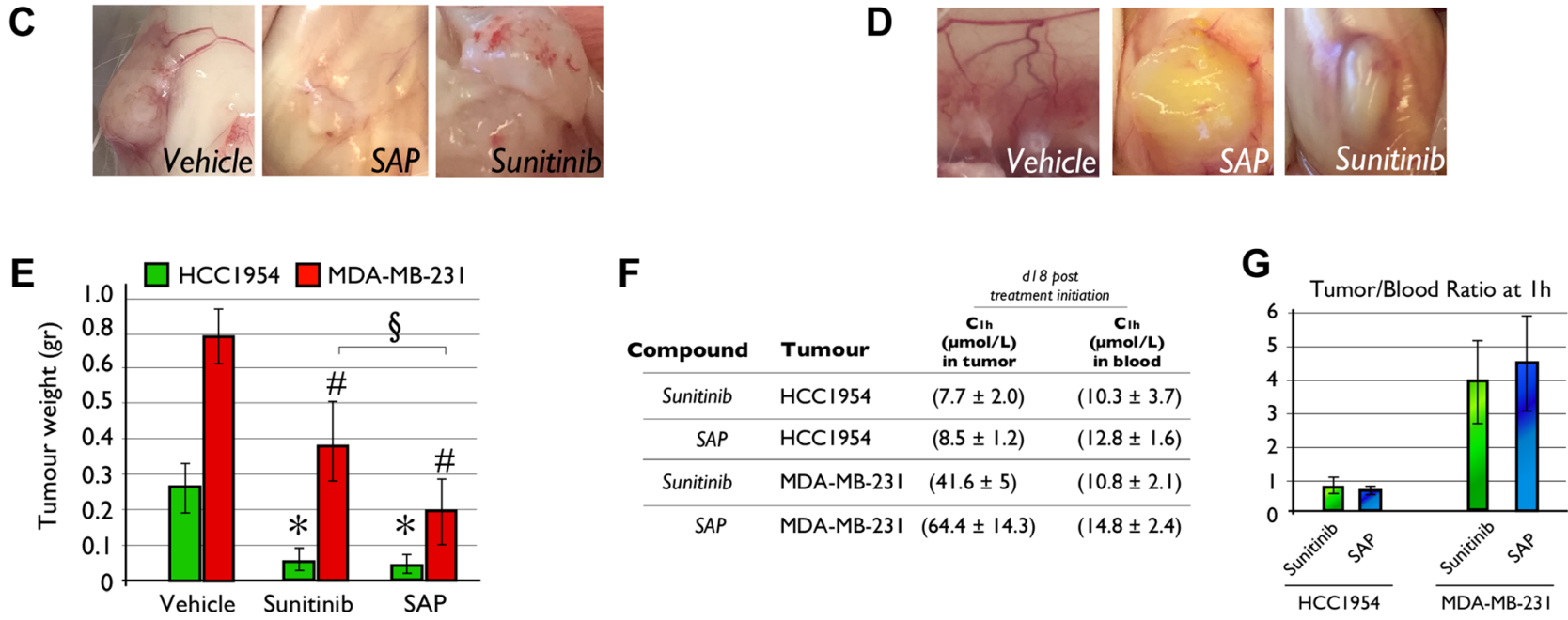

Figure 4: In vivo efficacy of SAP $(100 \mu \mathrm{mol} / \mathrm{Kg})$ versus equimolar amounts of sunitinib in NOD/SCID mice xenografted with (A) HCC1954 and (B) MDA-MB-231 cell lines. Mice were dosed (IP) daily with SAP, sunitinib or vehicle. Each point represents the mean of at least 10 tumor volumes resulting from at least five mice \pm SD. $* P<.001$, compared with the vehicle group by using one way ANOVA followed by the post hoc Turkey-Kramer multiple comparison test (C) Evidence of reduced neo-angiogenesis in HCC1954 and (D) MDAMB-231 xenografted tumors from SAP and sunitinib compared to vehicle treated mice. (E) Average tumor weight at day of sacrifice (d18) between treatment groups. Each bar is the average of 10 tumors for each treatment \pm SD. The * for the HCC1954 and ${ }^{\#}$ for the MDA-MB-231 cell line denote a $P<.001$, compared with their respective vehicle group while the $\S$ denotes a $P<.001$ between SAP and sunitinib, by using one way ANOVA followed by the post hoc Turkey-Kramer multiple comparison test. (F) Average intratumoral and blood drug levels as measured by LC-MS/MS at $1 \mathrm{~h}$ post a final dose on d18 ( $\pm \mathrm{SD})$. (G) Tumor/blood $(\mathrm{t} / \mathrm{b})$ ratio for SAP and sunitinib from the LC-MS/MS measurements. 
transgenic embryos EGFP expression is driven by the kdrl endothelial specific promoter representative of the VEGF signaling and marks all endothelial cells. In zebrafish embryos the intersomitic vessels (ISVs) are first marked by $k d r l: g f p$ labeling at $23 \mathrm{hpf}$, they are partially patent at $1.5 \mathrm{dpf}$ and they show robust circulation by $2 \mathrm{dpf}$. The results of the effect of equimolar SAP and sunitinib are shown in Figure 5G. No toxic or off-target morphological phenotypes were observed after $24 \mathrm{~h}$ treatment with $50 \mu \mathrm{M}$ SAP or sunitinib. Control (DMSO treated) embryos had their ISVs arranged in an extremely regular array, while treatment with $50 \mu \mathrm{M}$ sunitinib robustly inhibited angiogenic sprouting and no ISVs were present at $48 \mathrm{hpf}$. On the other hand, the ISVs of SAP treated embryos appeared to develop almost normally with minor ISV formation inhibition, which was more profound at $100 \mu \mathrm{M}$.
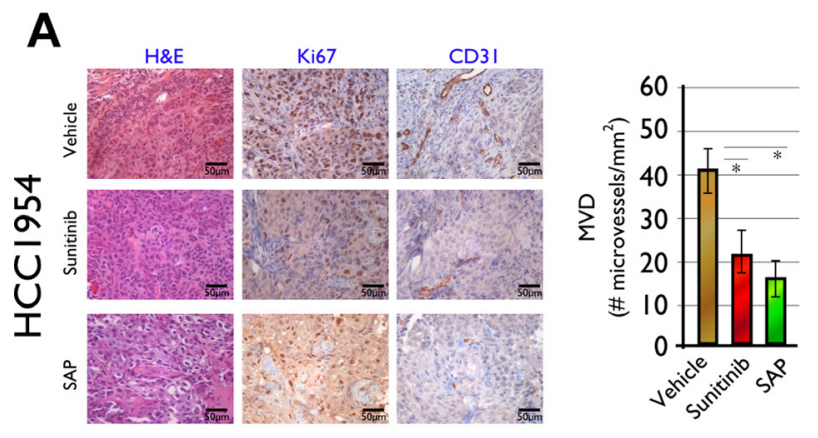

B
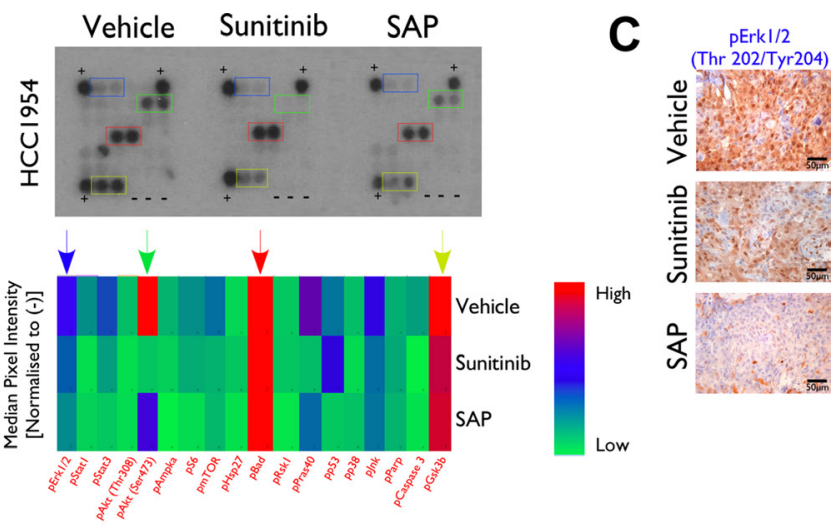

D
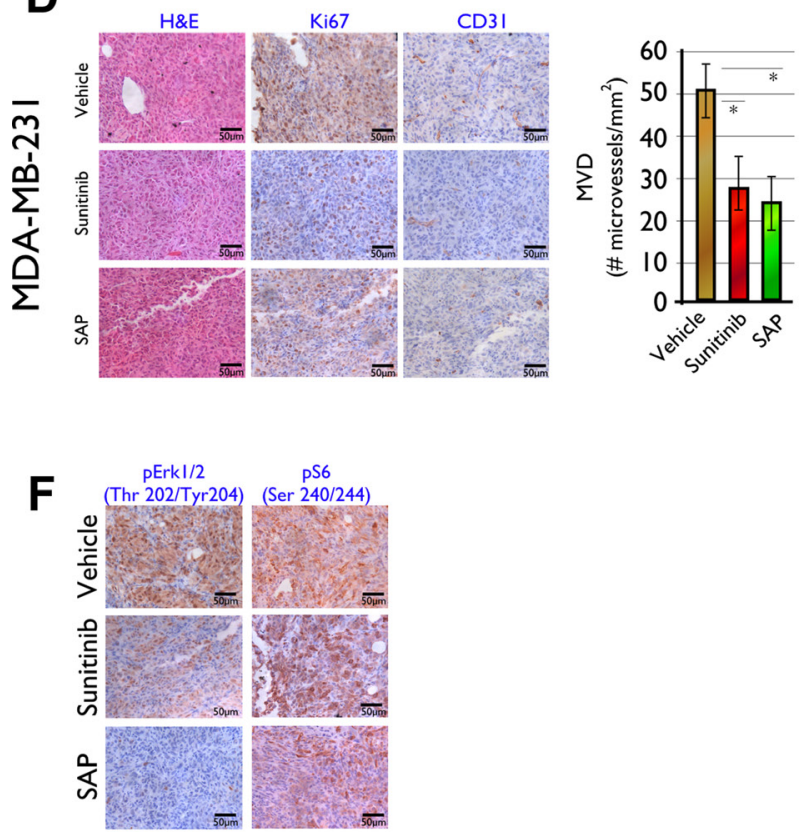
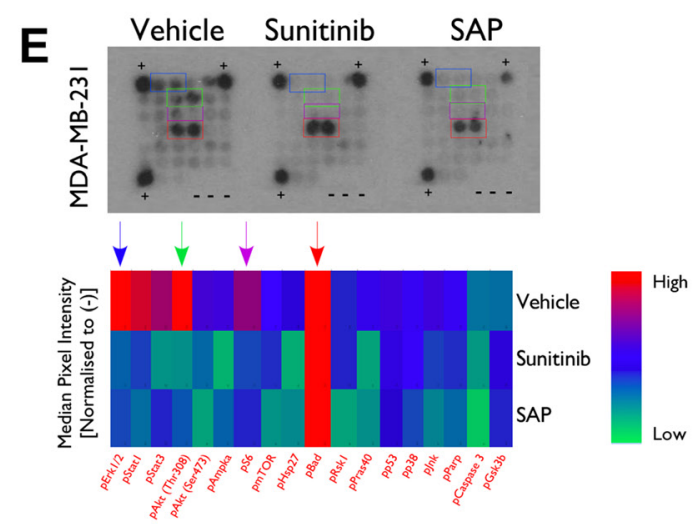

G

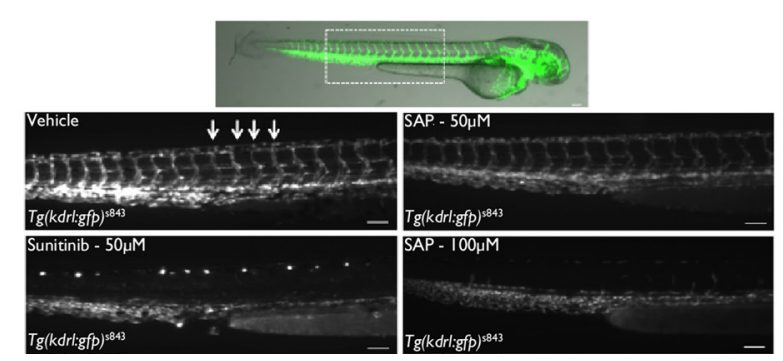

Figure 5: Histological and molecular investigation of SAP efficacy in (A-C) HCC1954 and (D-F) MDA-MB-231 tumor sections on d18 post treatment initiation. (A) Immunohistochemical analysis in HCC1954 tumor sections showed a marked decrease in cell proliferation (Ki-67) and angiogenesis (CD31) in SAP and sunitinib versus vehicle treated mice. (B) Heat map analysis of HCC1954 tissue lysate showing the in vivo phosphorylation status of 18 kinases for all treated mice. Data represent the average of 10 tumors from five mice for each treatment. Reduced levels of phosphorylated GSK3, Akt and Erk1/2 for SAP and sunitinib versus vehicle treated mice were detected and (C) verified for Erk1/2 by IHC. (D) A similar analysis in MDA-MB-231 xenografts revealed decreased proliferation and angiogenesis as well as (E) reduced phosphorylation of Akt, S6 and Erk1/2 for SAP and sunitinib over vehicle treated mice. (F) Reduced levels of phosphorylation for specific kinases were verified by IHC for Erk1/2 and S6. For each IHC photo, brown indicates DAB reaction product with representative $\mathrm{x} 40$ fields shown. Scale bar: $50 \mu \mathrm{m}$. (G) Inhibition of angiogenesis in Zebrafish from SAP and sunitinib. Overlay of fluorescent and bright field images of a vehicle treated (DMSO) $T g(k d r l: g f p)^{\text {s843 }}$ embryo at $48 \mathrm{hpf}$. The dotted line box indicates the location of the images shown in the other panels. Fluorescence microscopy images of $48 \mathrm{hpf}$ embryos treated from 24 to $48 \mathrm{hpf}$ with vehicle or $50 \mu \mathrm{M}$ of SAP or sunitinib and $100 \mu \mathrm{M}$ SAP. Vehicle and $50 \mu \mathrm{M}$ SAP treated embryos exhibited uniform GFP expression in intersomitic vessels identified with white arrows. Sunitinib at $50 \mu \mathrm{M}$ and SAP at $100 \mu \mathrm{M}$ inhibited angiogenic sprouting in the zebrafish trunk. Scale bar $100 \mu \mathrm{m}$. 
The observed lower efficacy from SAP was clarified following whole embryo LC-MS/MS biodistribution measurements that demonstrated an approximate 50\% uptake of the more hydrophilic SAP from fish embryos at $24 \mathrm{~h}$ post drug exposure, in contrast to more than $90 \%$ uptake of the more lipophilic sunitinib (data not shown).

\section{Toxicity assessment in rodents}

Considering the known cardiotoxicity of sunitinib and related molecules $[17,28]$, we assessed the cardiac function of vehicle or compound treated C57BL/6 female mice. Results showed that both SAP and sunitinib had a statistically significant \%FS (Fractional Shortening) reduction following treatment, with SAP appearing slightly more cardiotoxic than sunitinib (Figure 6A-6B). Mice treated with SAP had a $\%$ FS reduction from the baseline measurement of $47.48 \pm 0.91$ to $42.38 \pm 0.76$, $P<.0001$ at one week post treatment. The respective $\% \mathrm{FS}$ value for sunitinib dropped from $47.48 \pm 1.05$ to $45.42 \pm 0.11, P=.0047)$, whereas vehicle treated mice had a non-significant fall in $\% \mathrm{FS}$ (from $47.49 \pm 1.16$ to $46.34 \pm 0.56$ ) as shown in Figure 6B.

Hematotoxicity of SAP and sunitinib was also evaluated for all treated mice at the end of the cardiotoxicity experiments. Results indicated a mild but statistically non-significant difference in white blood cell populations between vehicle $\left(2.90 \pm 0.8 \times 10^{3}\right.$ cells $)$, sunitinib $\left(2.24 \pm 0.5 \times 10^{3}\right.$ cells $)$ and SAP $\left(2.54 \pm 1.0 \times 10^{3}\right.$ cells) treated mice (Figure 6C). All other blood parameters measured remained constant, concluding that SAP had a similar hematotoxic profile with sunitinib under the specific experimental conditions.

\section{In vivo antitumor efficacy in syngeneic BrCa animal models}

Despite the efficacy and favourable safety profile of SAP in xenografted models of primary BrCa, a critical question that remained was its evaluation in a more clinically relevant disease model of $\mathrm{BrCa}$ that would involve interaction of cancer with the immune system, which is crucial for the progression of the disease. Thus we generated syngeneic animal models of $\mathrm{BrCa}$ in $\mathrm{C} 57 \mathrm{BL} / 6$ immunocompetent mice using the E0771 BrCa murine cell line, which has been successfully used previously to evaluate sunitinib [29]. Equimolar amounts of SAP and sunitinib were evaluated in either the ectopic (Figure 7A) or orthotopic (Figure 7B) E0771 implantation setting using animals with identical genetic backgrounds, with results showing a significant tumour growth inhibition from both SAP and sunitinib $(P<.01)$ in both cases in contrast to vehicle treated animals that had to be ethically sacrificed (at day 11) due to a heavy tumour burden. Upon sacrifice
A

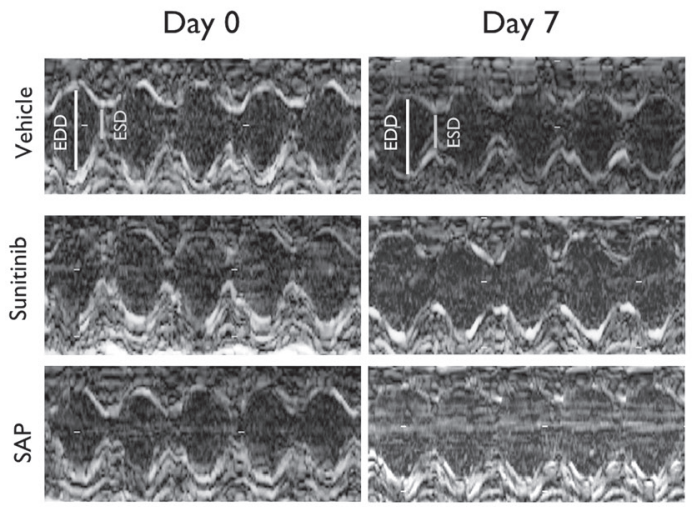

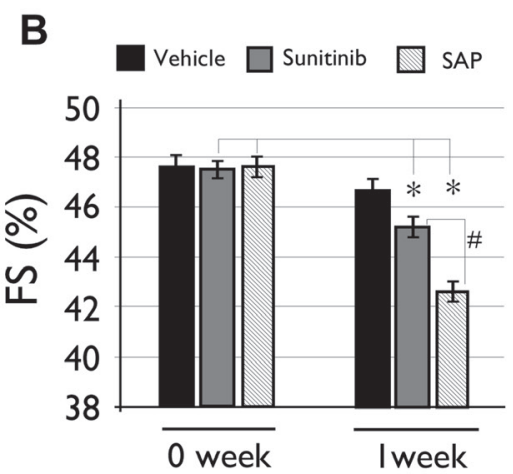

$* p<0.005$ vs baseline at 0 week \# $\mathrm{p}<0.00$ I SAP vs Sunitinib at I week

C
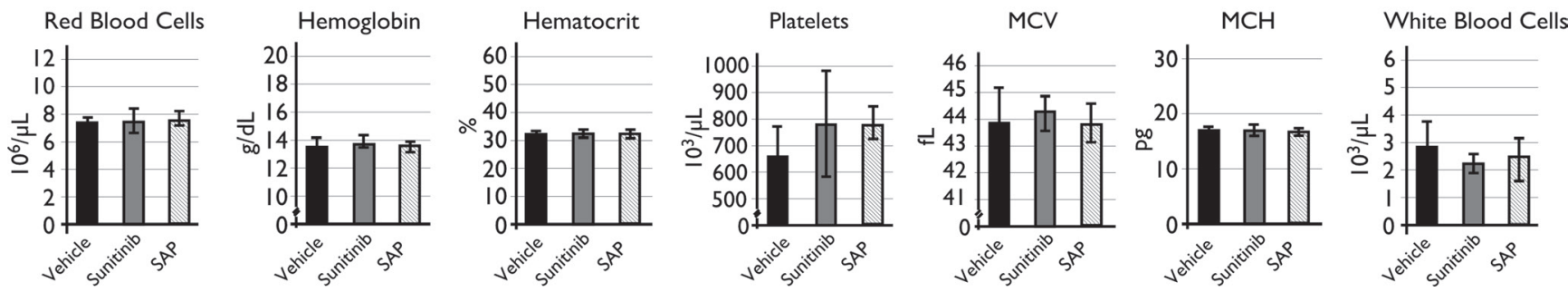

Figure 6: Toxicity evaluation of SAP. (A) Cardiac LV function echocardiography measurements with representative M-mode echocardiograms and (B) \%FS reduction compared to baseline levels at one week of treatment. Data are expressed as mean \pm SD and a $P<.005$ value was considered statistically significant. (C) Hematological analysis of the same C57BL/6 mice used for the cardiotoxicity experiments. Each column is the mean of at least eight mice $\pm \mathrm{SD}$ with a $P<.05$ value considered statistically significant. MCV: mean cell volume; MCH: mean cell hemoglobin. 
no macroscopic metastatic lesion was observed in any of the treated mice, despite the high metastatic potential of this particular model [30].

\section{DISCUSSION}

An underlying assumption regarding the rationale for using antiangiogenic therapies is that all types of cancer are angiogenesis-dependent and therefore inhibiting angiogenesis would be highly effective as a generic cancer treatment. However, in retrospect this rationale is valid for highly angiogenic types of cancer where VEGF is a key proangiogenic molecule [31] and sunitinib is an established therapy but in $\mathrm{BrCa}$ this may not be applicable. Furstenberger et al. recently analyzed the expression of a dozen different proangiogenic growth factors in 41 samples of primary $\mathrm{BrCa}$ tissue specimens and normal adjacent tissues [32], and discovered that 11/12 factors analyzed showed greater levels of gene expression in the adjacent normal tissue with VEGF being the only exception. These results could expound the shortcomings of antiangiogenic molecules in the various $\mathrm{BrCa}$ clinical trials $[14,15]$ and also highlight the importance of selecting the most appropriate population of patients to treat with a particular agent, since some patients with metastatic $\mathrm{BrCa}$ do benefit from antiangiogenic agents over others. Certainly, an important parameter to consider when treating $\mathrm{BrCa}$ with antiangiogenic agents is the reported drug induced tumor hypoxia (through upregulation of Hypoxia Inducible Factor, HIF) and an increase in cancer stem cells that promote drug resistance and disease progression [10]. However, a similar effect is also observed for cytotoxic agents [33] suggesting that hypoxia is a key feature in $\mathrm{BrCa}$ and combinational treatment regimes including an HIF inhibitor should be evaluated [34]. Thus, several reports justify that antiangiogenic therapy still holds a future in $\mathrm{BrCa}$ treatment [13]. It seems plausible that angiogenesis in $\mathrm{BrCa}$ may be better addressed by blocking

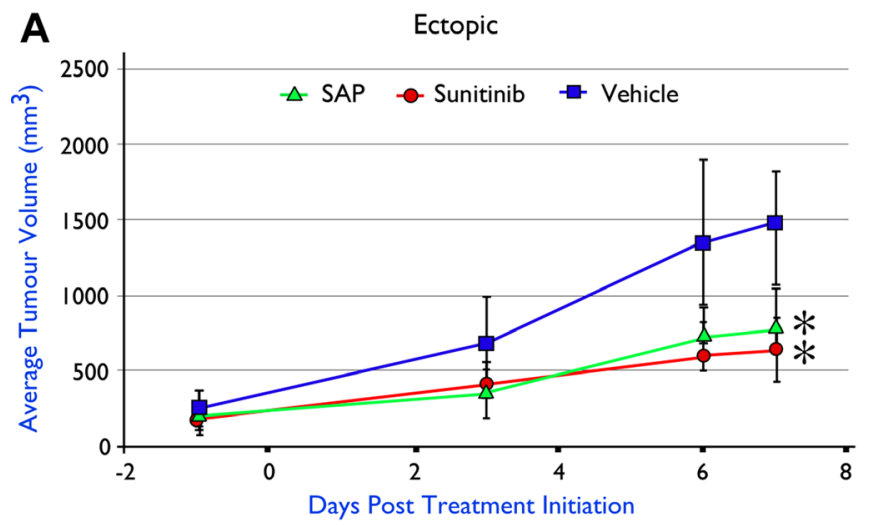

several antiangiogenic signaling pathways, such as STAT, TGF- $\beta$ or Notch, rather than simply the VEGFR [35].

One such rationally designed and readily conjugatable molecule is presented here (SAP), which proved potent in vivo in four different animal models of $\mathrm{BrCa}$. The clinical shortcomings of sunitinib in $\mathrm{BrCa}$ suggest that SAP (and similar agents) will most likely be evaluated in a combinational scheme with molecules targeting other critical tumour pathways. Interestingly, in vitro data showed that SAP inhibited one such target that is overexpressed in a subset of ER-positive $\mathrm{BrCa}$ (RET), and that crosstalk between RET and ER is important in responses to endocrine therapy [38]. Thus SAP could represent a promising molecule active in various ER positive subtypes of $\mathrm{BrCa}$ independent of VEGFR inhibition, deserving future investigation as a strategy to prevent endocrine resistance [39].

An important aspect of SAP development was the absence of hematotoxicity in all treated animals, while the observed mild cardiotoxicity was certainly a point of concern irrespective of its severity. We had previously encountered a related cardiotoxic incident with another analogue of sunitinib (SAN1) [18] but this effect was alleviated when SAN1 was conjugated to a peptide moiety. It seems reasonable to assume that the same outcome could be achieved with SAP in future conjugation studies of SAP with a targeting moiety. Such conjugation studies are expected to decrease off-target toxicities and increase tumour biodistribution of the SAP pharmacophore.

A critical aspect of SAP evaluation was its efficacy in syngeneic animal models. A long-standing problem in drug development is the frequent failure of preclinical animal models of disease to accurately predict clinical activity $[40,41]$. Although there are important differences between humans and mice, at least this model maintains the homogeneity of $\mathrm{BrCa}$ derived from a genetic background similar to the host animal [42], ensuring that the immune response and cancer-host interactions are

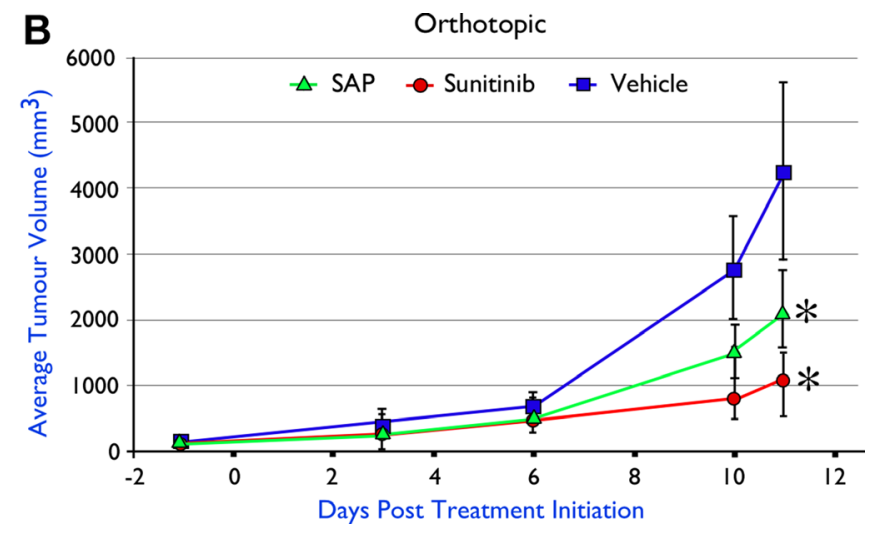

Figure 7: In vivo efficacy of SAP $(100 \mu \mathrm{mol} / \mathrm{Kg})$ versus equimolar amounts of sunitinib in C57BL/6 mice with implanted E0771 murine BrCa cell line (A) ectopically $(n=5)$ and $(\mathbf{B})$ orthotopically $(n=6)$. Each point represents the mean of 10 (ectopic) and 6 (orthotopic) tumor volumes $\pm \mathrm{SD}$. ${ }^{*} P<.001$, compared with the vehicle group by using one way ANOVA followed by the post hoc Turkey-Kramer multiple comparison test. 
more faithfully preserved than in the xenograft animal models. Certainly the syngeneic model has its limitations with important differences in the stroma as well as in the innate and adaptive immunity between mice and human, but the fact that SAP inhibited tumour growth is certainly a strong point towards its further development.

In conclusion we have generated a potent sunitinib based analogue characterized by some advantages over the parental molecule including improved solubility, enhanced pharmacokinetic parameters in mice and the ability to be readily conjugated to a targeting peptide or antibody.

\section{MATERIALS AND METHODS}

\section{Chemicals, synthesis and characterization of SAP}

All chemicals were purchased from SigmaAldrich, while sunitinib was from Selleckchem, USA. SAP was synthesized as shown in Figure 1 and described in the Supplementary Materials sections (S.I.1). Mass Spectrometry (MS) was employed to define the key spectral features necessary for the quantification of all molecules in blood and tissue as described previously $[43,44]$. Total polar surface area (PSA) and $\operatorname{clog} P$ values were predicted by Chemdraw Ultra (v10, PerkinElmer Informatics). The GSTfusion proteins and the antibodies used for this study are summarized in Supplementary Tables 1 and 2 respectively.

\section{Computational methods}

Detailed docking and molecular dynamic analysis for all the compounds is described in the S.I.2.

\section{In vitro evaluation}

The trans-phosphorylation activity of VEGFR-2, PDGFR- $\beta$, KIT, FLT3, RET and EGFR was evaluated as described before [45]. Detailed methods and a list of the kinases used are available in the S.I.3. Cellular inhibition of autophosphorylation of VEGFR-2 and PDGFR- $\beta$ was performed as described in the S.I.4. For cellular studies, cells were used within six months of purchase and were cultured as instructed by the American Type Culture Collection (ATCC-LGC Standards, Germany). All cell lines were obtained from the ATCC while HUVEC were from Life Technologies. E0771 cells were a kind gift of Dr Fernando Rodriguez-Serrano (University of Granada) and were grown as described previously [46]. Cell toxicity was measured by the MTT assay [44, 47].

\section{Pharmacokinetic analysis}

All animal procedures were approved by the Bioethical Committee of BRFAA based on the European
Directive 86/609. For pharmacokinetic studies, female NOD/ SCID mice (Charles River, Italy) were used (8-10 weeks old, $n=6$ per group). Dosing solutions of SAP $(100 \mu \mathrm{mol} / \mathrm{Kg})$ were prepared in 20\% 2-hydroxypropyl $\beta$-Cyclodextrin in sterile water (HP-b-CD). SAP was administered intraperitoneally (IP) or orally and blood samples were collected and prepared as described previously [43].

\section{In vivo efficacy}

For the xenograft studies, female NOD/SCID mice were injected in each flank with $3 \times 10^{6} \mathrm{HCC} 1954$ (HER2 amplified) or MDA-MB-231 (TNBC) cells, while for the syngeneic animal model $1 \times 10^{6}$ E0771 cells were implanted ectopically in the flanks or orthotopicaly in the fat-pad of the right inguinal mammary gland in female C57BL/6 mice as described before [48]. In every case pharmacological treatment was initiated when tumors reached $100-150 \mathrm{~mm}^{3}$ by daily IP administrations of sunitinib or equimolar doses of SAP $(100 \mu \mathrm{mol} / \mathrm{Kg}$, in HP-b-CD). Control mice received HP-b-CD while tumor growth and phenotypic signs of discomfort such as altered behaviour, guarding, mutilation or loss of appetite were constantly monitored during the course of treatment. Experiments were terminated after 18 days, at $1 \mathrm{~h}$ after the last administered dose by euthanizing the animals under isoflurane anesthesia. Tumors were excised, weighed and prepared for kinase activity, histopathology, immunohistochemistry (IHC) and quantification of compounds of interest by LC-MS/MS.

\section{Immunohistochemistry}

Excised tumors were fixed in neutral buffered formalin, paraffin embedded, sectioned and stained against CD31, Ki-67, pErk1/2 and pS6. Microvessel density was assessed by counting the number of CD31+ vessels in a $40 \times$ microscope field in a blinded fashion and presented as the amount of blood vessels $/ \mathrm{mm}^{2}$. To determine proliferation indices (PI), Ki67 positive or negative cells were counted using ImageJ software (US National Institutes of Health) in 3-4 representative fields of five tumors for each treatment (on average, $\sim 900$ nuclei were counted per specimen). Images were acquired by a Leica DFC350-FX camera mounted on a Leica DMLS2 microscope.

\section{In vivo kinase activity}

The PathScan intracellular signaling array kit (Cell Signaling, UK) was used as per manufacturer's direction to detect the phosphorylation status in supernatants from tumor extracts ( $n=10$ for each treatment). Images were analyzed with ImageJ software (v1.28) by loading the image as a gray scale picture and the average intensity for each kinase was calculated as described previously [49]. 


\section{Toxicity evaluation}

C57BL/6 female mice $(n=8)$ were used, treated for one week with daily IP administrations of HP-b$\mathrm{CD}$ or $100 \mu \mathrm{mol} / \mathrm{Kg}$ of SAP or sunitinib. Cardiotoxicity was assessed as described previously [18, 50]. For the hematotoxicity experiments approximately $300 \mu \mathrm{L}$ of blood were collected from each animal in a vacutainer blood collection tube containing EDTA (BD Biosciences). Blood analysis was performed directly after sampling in a MEK-6318J/K hematology analyzer (Nihon Kohden Corp, Japan) and the parameters measured were red and white blood cell numbers, platelets hemoglobin, hematocrit, mean cell volume (MCV) and mean cell hemoglobin.

\section{Zebrafish experiments}

Zebrafish embryos were maintained and raised as described previously [51]. The experimental protocols described in this study were carried out with zebrafish larvae up to $96 \mathrm{~h}$ post fertilization (hpf) and therefore are not subject to the regulations of European animal protection guidelines. The $T g(k d r l: g f p)^{\mathrm{s} 483}$ transgenic line was used. For the bioaccumulation experiments, synchronized $24 \mathrm{hpf} T g(k d r l: g f p)^{s 483}$ embryos were exposed to $50 \mu \mathrm{M}$ sunitinib or SAP with final concentration $0.1 \%$ $(\mathrm{v} / \mathrm{v})$ DMSO (vehicle) in embryo medium $(0.3 \mathrm{~g} / \mathrm{L}$ "Instant Ocean" Sea Salts and $0.08 \mathrm{~g} / \mathrm{L} \mathrm{CaSO}_{4} * 2 \mathrm{H}_{2} \mathrm{O}$ ). Treatments were performed in three independent experiments with 50 embryos per experimental sample. Embryo and water samples were collected at $1 \mathrm{~min}$ and $24 \mathrm{~h}$ post treatment. After exposure, embryos were rinsed with fresh embryo medium, snap frozen in liquid nitrogen and stored at $-80^{\circ} \mathrm{C}$. For monitoring the antiangiogenic activity of SAP and sunitinib $T g(k d r l: g f p)^{s 483}$ embryos were treated at $24 \mathrm{hpf}$ with $50 \mu \mathrm{M}$ of the compounds or vehicle and images were taken at $48 \mathrm{hpf}$.

\section{Statistical analyses}

Statistical analyses and calculation of all $\mathrm{IC}_{50} \mathrm{~s}$ were performed by SigmaPlot12 software and statistical significance was determined using the Student's two-tailed, two-sample unequal variance distribution $t$ test. Comparison of means among three study groups was made by using one-way ANOVA followed by the post hoc Turkey-Kramer multiple comparison test using StatPlus (v6, Analysoft). A two-sided $(P<.01)$ was considered statistically significant.

\section{ACKNOWLEDGMENTS AND FUNDING}

We would like to thank Dr Fernando RodriguezSerrano of the Institute of Biopathology and Regenerative medicine, University of Granada for providing the E0771 cell line. We would also like to thank the BRFAA colleagues Dr Dimitris Stellas for performing the orthotopic injections in C57BL/6 mice, Mrs Ismini Kloukina for tumour tissue sectioning and especially Ms Aikaterini Kalargyrou for technical advice on Western blot, inspiration and support.

\section{CONFLICTS OF INTEREST}

The authors declare that they have no conflicts of interest to disclose.

\section{FINANCIAL SUPPORT}

This work was co-funded by the Greek Ministry of Education, National Strategic Reference Framework (NSRF) 2007-2013 under grants "PostDoc - DENTADPROCAT" (LS7-1682/17156/6.12.10) and "Aristeia II" (2334/26-02-2014)"

\section{REFERENCES}

1. Di Cosimo S, Baselga J. Management of breast cancer with targeted agents: importance of heterogeneity. Nat Rev Clin Oncol. 2010; 7:139-147.

2. Higgins MJ, Baselga J. Targeted therapies for breast cancer. J Clin Invest. 2011; 121:3797-3803.

3. Criscitiello C, Azim HA Jr, Schouten PC, Linn SC, Sotiriou C. Understanding the biology of triple-negative breast cancer. Ann Oncol. 2012; 23:vi13-18.

4. Eroles P, Bosch A, Perez-Fidalgo JA, Lluch A. Molecular biology in breast cancer: intrinsic subtypes and signaling pathways. Cancer Treat Rev. 2012; 38:698-707.

5. Zardavas D, Baselga J, Piccart M. Emerging targeted agents in metastatic breast cancer. Nat Rev Clin Oncol. 2013; 10:191-210.

6. Folkman J. Tumor angiogenesis: therapeutic implications. N Engl J Med. 1971; 285:1182-1186.

7. Bicknell R. Targeting angiogenesis with monoclonal antibodies. Ann Oncol. 2006; 17 Suppl 10:x76-78.

8. Jayson GC, Kerbel R, Ellis LM, Harris AL. Antiangiogenic therapy in oncology: current status and future directions. Lancet. 2016; 388:518-529.

9. Chinchar E, Makey K, Gibson J, Chen F, Cole S, Megason G, Vijayakumar S, Miele L, Gu J. Sunitinib significantly suppresses the proliferation, migration, apoptosis resistance, tumor angiogenesis and growth of triple-negative breast cancers but increases breast cancer stem cells. Vasc Cell. 2014; 6.

10. Conley SJ, Gheordunescu E, Kakarala P, Newman B, Korkaya H, Heath AN, Clouthier SG, Wicha MS. Antiangiogenic agents increase breast cancer stem cells via the generation of tumor hypoxia. Proc Natl Acad Sci U S A. 2012; 109:2784-2789.

11. Theze B, Bernards N, Beynel A, Bouet S, Kuhnast B, Buvat I, Tavitian B, Boisgard R. Monitoring therapeutic 
efficacy of sunitinib using [(18)F]FDG and [(18)F]FMISO PET in an immunocompetent model of luminal B (HER2positive)-type mammary carcinoma. BMC Cancer. 2015; 15:534.

12. Zhang D, Sun B, Zhao X, Ma Y, Ji R, Gu Q, Dong X, Li J, Liu F, Jia X, Leng X, Zhang C, Sun R, et al. Twist1 expression induced by sunitinib accelerates tumor cell vasculogenic mimicry by increasing the population of CD133+ cells in triple-negative breast cancer. Mol Cancer. 2014; 13:207.

13. Rugo HS. Inhibiting angiogenesis in breast cancer: the beginning of the end or the end of the beginning? J Clin Oncol. 2012; 30:898-901.

14. Bergh J, Bondarenko IM, Lichinitser MR, Liljegren A, Greil R, Voytko NL, Makhson AN, Cortes J, Lortholary A, Bischoff J, Chan A, Delaloge S, Huang X, et al. Firstline treatment of advanced breast cancer with sunitinib in combination with docetaxel versus docetaxel alone: results of a prospective, randomized phase III study. J Clin Oncol. 2012; 30:921-929.

15. Crown JP, Dieras V, Staroslawska E, Yardley DA, Bachelot T, Davidson N, Wildiers H, Fasching PA, Capitain O, Ramos M, Greil R, Cognetti F, Fountzilas G, et al. Phase III trial of sunitinib in combination with capecitabine versus capecitabine monotherapy for the treatment of patients with pretreated metastatic breast cancer. J Clin Oncol. 2013; 31:2870-2878.

16. Bachelot T, Garcia-Saenz JA, Verma S, Gutierrez M, Pivot X, Kozloff MF, Prady C, Huang X, Khosravan R, Wang Z, Cesari R, Tassell V, Kern KA, et al. Sunitinib in combination with trastuzumab for the treatment of advanced breast cancer: activity and safety results from a phase II study. BMC Cancer. 2014; 14:166.

17. Chintalgattu V, Rees ML, Culver JC, Goel A, Jiffar T, Zhang J, Dunner K Jr, Pati S, Bankson JA, Pasqualini R, Arap W, Bryan NS, Taegtmeyer H, et al. Coronary microvascular pericytes are the cellular target of sunitinib malate-induced cardiotoxicity. Sci Transl Med. 2013; 5:187ra169.

18. Argyros O, Karampelas T, Asvos X, Varela A, Sayyad N, Papakyriakou A, Davos CH, Tzakos AG, Fokas D, Tamvakopoulos C. Peptide-Drug Conjugate GnRHSunitinib Targets Angiogenesis Selectively at the Site of Action to Inhibit Tumor Growth. Cancer Res. 2016; 76:1181-1192.

19. Chen K, Fang Z, Yang Z. Design, Synthesis and Biological Evaluation of Sunitinib Analogues to Improve Aqueous Solubility. Advanced Material Research. 2014; 749:350-353.

20. London CA, Malpas PB, Wood-Follis SL, Boucher JF, Rusk AW, Rosenberg MP, Henry CJ, Mitchener KL, Klein MK, Hintermeister JG, Bergman PJ, Couto GC, Mauldin GN, et al. Multi-center, placebo-controlled, double-blind, randomized study of oral toceranib phosphate (SU11654), a receptor tyrosine kinase inhibitor, for the treatment of dogs with recurrent (either local or distant) mast cell tumor following surgical excision. Clin Cancer Res. 2009; 15:3856-3865.

21. Noh GT, Kim MH, Suh JY, Song Y, Lee CK, Baek JH, Lee YS, Cho G, Kim E, Kim YR, Cho HJ, Lim D, Kim JK. Sunitinib--CLIO conjugate: a VEGFR/PDGFR-targeting active MR probe. Mol Imaging Biol. 2014; 16:340-349.

22. Patyna S, Laird AD, Mendel DB, O'Farrell AM, Liang C, Guan H, Vojkovsky T, Vasile S, Wang X, Chen J, Grazzini M, Yang CY, Haznedar JO, et al. SU14813: a novel multiple receptor tyrosine kinase inhibitor with potent antiangiogenic and antitumor activity. Mol Cancer Ther. 2006; 5:1774-1782.

23. Prakash $\mathrm{C}$, Theivendren P. Indolin-2-Ones in Clinical Trials as Potential Kinase Inhibitors: A Review. Pharmacology \& Pharmacy. 2012; 3:62-71.

24. Chopra A, Anderson A, Giardina C. Novel piperazinebased compounds inhibit microtubule dynamics and sensitize colon cancer cells to tumor necrosis factor-induced apoptosis. J Biol Chem. 2014; 289:2978-2991.

25. She EX, Hao Z. A novel piperazine derivative potently induces caspase-dependent apoptosis of cancer cells via inhibition of multiple cancer signaling pathways. Am J Transl Res. 2013; 5:622-633.

26. Patel RV, Park SW. An evolving role of piperazine moieties in drug design and discovery. Mini Rev Med Chem. 2013; 13:1579-1601.

27. Remko M, Bohac A, Kovacikova L. Molecular structure, pKa, lipophilicity, solubility, absorption, polar surface area, and blood brain barrier penetration of some antiangiogenic agents. Struct Chem. 2011; 22:635-648.

28. Force T, Kolaja KL. Cardiotoxicity of kinase inhibitors: the prediction and translation of preclinical models to clinical outcomes. Nat Rev Drug Discov. 2011; 10:111-126.

29. Young E, Miele L, Tucker KB, Huang M, Wells J, Gu JW. SU11248, a selective tyrosine kinases inhibitor suppresses breast tumor angiogenesis and growth via targeting both tumor vasculature and breast cancer cells. Cancer Biol Ther. 2010; 10:703-711.

30. Johnstone CN, Smith YE, Cao Y, Burrows AD, Cross RS, Ling X, Redvers RP, Doherty JP, Eckhardt BL, Natoli AL, Restall CM, Lucas E, Pearson HB, et al. Functional and molecular characterisation of EO771.LMB tumours, a new C57BL/6-mouse-derived model of spontaneously metastatic mammary cancer. Dis Model Mech. 2015; 8:237-251.

31. Baldewijns MM, Thijssen VL, Van den Eynden GG, Van Laere SJ, Bluekens AM, Roskams T, van Poppel H, De Bruine AP, Griffioen AW, Vermeulen PB. High-grade clear cell renal cell carcinoma has a higher angiogenic activity than low-grade renal cell carcinoma based on histomorphological quantification and qRT-PCR mRNA expression profile. Br J Cancer. 2007; 96:1888-1895.

32. Furstenberger G, von Moos R, Lucas R, Thurlimann B, Senn HJ, Hamacher J, Boneberg EM. Circulating endothelial cells and angiogenic serum factors during 
neoadjuvant chemotherapy of primary breast cancer. Br J Cancer. 2006; 94:524-531.

33. Samanta D, Gilkes DM, Chaturvedi P, Xiang L, Semenza GL. Hypoxia-inducible factors are required for chemotherapy resistance of breast cancer stem cells. Proc Natl Acad Sci U S A. 2014; 111:E5429-5438.

34. Yehia L, Boulos F, Jabbour M, Mahfoud Z, Fakhruddin N, El-Sabban M. Molecular Subtypes: Expression of HIF-1 alpha and Markers of Angiogenesis Are Not Significantly Different in Triple Negative Breast Cancer Compared to Other Breast Cancer Implications for Future Therapy. PLoS One. 2015; 10:1-14.

35. Patel A, Hielscher A. Angiogenesis Inhibitors in the Treatment of Breast Cancer: Exploring Avenues of New Therapeutic Targets. Journal of Cancer Prevention \& Current Research. 2015; 2.

36. Karampelas T, Argyros O, Sayyad N, Spyridaki K, Pappas C, Morgan K, Kolios G, Millar RP, Liapakis G, Tzakos AG, Fokas D, Tamvakopoulos C. GnRHGemcitabine conjugates for the treatment of androgenindependent prostate cancer: pharmacokinetic enhancements combined with targeted drug delivery. Bioconjug Chem. 2014; 25:813-823.

37. Liu SV, Tsao-Wei DD, Xiong S, Groshen S, Dorff TB, Quinn DI, Tai YC, Engel J, Hawes D, Schally AV, Pinski JK. Phase I, dose-escalation study of the targeted cytotoxic LHRH analog AEZS-108 in patients with castration- and taxane-resistant prostate cancer. Clin Cancer Res. 2014; 20:6277-6283.

38. Mulligan LM. RET revisited: expanding the oncogenic portfolio. Nat Rev Cancer. 2014; 14:173-186.

39. Morandi A, Plaza-Menacho I, Isacke CM. RET in breast cancer: functional and therapeutic implications. Trends Mol Med. 2011; 17:149-157.

40. Guerin E, Man S, Xu P, Kerbel RS. A model of postsurgical advanced metastatic breast cancer more accurately replicates the clinical efficacy of antiangiogenic drugs. Cancer Res. 2013; 73:2743-2748.

41. Kerbel RS. A Decade of Experience in Developing Preclinical Models of Advanced- or Early-Stage Spontaneous Metastasis to Study Antiangiogenic Drugs, Metronomic Chemotherapy, and the Tumor Microenvironment. Cancer J. 2015; 21:274-283.

42. Rashid OM, Takabe K. Animal models for exploring the pharmacokinetics of breast cancer therapies. Expert Opin Drug Metab Toxicol. 2015; 11:221-230.

43. Argyros O, Lougiakis N, Kouvari E, Papafotika A, Raptopoulou CP, Psycharis V, Christoforidis S, Pouli N,
Marakos P, Tamvakopoulos C. Design and synthesis of novel 7-aminosubstituted pyrido[2,3-b]pyrazines exhibiting anti-breast cancer activity. Eur J Med Chem. 2017; 126:954-968.

44. Karampelas T, Skavatsou E, Argyros O, Fokas D, Tamvakopoulos C. Gemcitabine Based Peptide Conjugate with Improved Metabolic Properties and Dual Mode of Efficacy. Mol Pharm. 2017; 14:674-685.

45. Sun L, Liang C, Shirazian S, Zhou Y, Miller T, Cui J, Fukuda JY, Chu JY, Nematalla A, Wang X, Chen H, Sistla A, Luu TC, et al. Discovery of 5-[5-fluoro-2-oxo-1,2dihydroindol-(3Z)-ylidenemethyl]-2,4- dimethyl-1H-pyrrole-3 -carboxylic acid (2-diethylaminoethyl)amide, a novel tyrosine kinase inhibitor targeting vascular endothelial and plateletderived growth factor receptor tyrosine kinase. J Med Chem. 2003; 46:1116-1119.

46. Carrasco E, Garrido JM, Alvarez PJ, Alvarez-Manzaneda E, Chahboun R, Messouri I, Melguizo C, Aranega A, Rodriguez-Serrano F. Meroxest improves the prognosis of immunocompetent C57BL/6 mice with allografts of E0771 mouse breast tumor cells. Arch Med Sci. 2016; 12:919-927.

47. Daniilides K, Lougiakis N, Evangelidis T, Kostakis IK, Pouli N, Marakos P, Mikros E, Skaltsounis AL, Bach S, Baratte B, Ruchaud S, Karamani V, Papafotika A, et al. Discovery of new aminosubstituted pyrrolopyrimidines with antiproliferative activity against breast cancer cells and investigation of their effect towards the PI3Kalpha enzyme. Anticancer Agents Med Chem. 2016 Dec 7. [Epub ahead of print].

48. Stivarou T, Stellas D, Vartzi G, Thomaidou D, Patsavoudi E. Targeting highly expressed extracellular HSP90 in breast cancer stem cells inhibits tumor growth in vitro and in vivo. Cancer Biol Ther. 2016;17:799-812.

49. Breitkopf SB, Yuan M, Pihan GA, Asara JM. Detection of a rare BCR-ABL tyrosine kinase fusion protein in H929 multiple myeloma cells using immunoprecipitation (IP)tandem mass spectrometry (MS/MS). Proc Natl Acad Sci USA. 2012; 109:16190-16195.

50. Psarras S, Mavroidis M, Sanoudou D, Davos CH, Xanthou G, Varela AE, Panoutsakopoulou V, Capetanaki Y. Regulation of adverse remodelling by osteopontin in a genetic heart failure model. Eur Heart J. 2012; 33:1954-1963.

51. Papakyriakou A, Kefalos P, Sarantis P, Tsiamantas C, Xanthopoulos KP, Vourloumis D, Beis D. A zebrafish in vivo phenotypic assay to identify 3-aminothiophene-2carboxylic acid-based angiogenesis inhibitors. Assay Drug Dev Technol. 2014; 12:527-535. 